\title{
Papers
}

\section{Reduced incidence of admissions for myocardial infarction associated with public smoking ban: before and after study}

\author{
Richard P Sargent, Robert M Shepard, Stanton A Glantz
}

\begin{abstract}
Objective To determine whether there was a change in hospital admissions for acute myocardial infarction while a local law banning smoking in public and in workplaces was in effect. Design Analysis of admissions from December 1997 through November 2003 using Poisson analysis.

Setting Helena, Montana, a geographically isolated community with one hospital serving a population of 68140 .

Participants All patients admitted for acute myocardial infarction.

Main outcome measures Number of monthly admissions for acute myocardial infarction for people living in and outside Helena.

Results During the six months the law was enforced the number of admissions fell significantly ( -16 admissions, 95\% confidence interval -31.7 to -0.3 ), from an average of 40 admissions during the same months in the years before and after the law to a total of 24 admissions during the six months the law was in effect. There was a non-significant increase of 5.6 ( -5.2 to 16.4) in the number of admissions from outside Helena during the same period, from 12.4 in the years before and after the law to 18.0 while the law was in effect.

Conclusions Laws to enforce smoke-free workplaces and public places may be associated with an effect on morbidity from heart disease.
\end{abstract}

\section{Introduction}

Secondhand smoke increases the risk of acute myocardial infarction. ${ }^{1-7}$ Smoking also increases the risk of acute myocardial infarction, but this risk falls rapidly after people stop smoking. The effects of secondhand smoke on platelets and the endothelium both occur rapidly (within 30 minutes) and are nearly as large in passive as in active smokers. ${ }^{125}$ The reductions in heart rate variability that occur with two hours of exposure increase the risk of myocardial infarction by around $10 \% .{ }^{9}$ Ordinances that end smoking in workplaces and public places both eliminate exposure to secondhand smoke and reduce the prevalence of smoking and cigarette consumption. ${ }^{10}$ We examined whether enactment of legislation to require smoke-free workplaces and public places was associated with a decline in hospital admissions for acute myocardial infarction. ${ }^{11}$

Helena, Montana, is a geographically isolated community in the United States that imposed such a law from 5 June 2002. Opponents won a court order suspending enforcement of the law on 3 December 2002. This allowed us to examine the association of the ordinance with admissions for myocardial infarction from within Helena (intervention) and from outside Helena, where the ordinance did not apply (control).

\section{Methods}

St Peter's Community Hospital serves all heart patients in Helena and the surrounding area, with a total population of 68140 . It is nearly $100 \mathrm{~km}$ to the next nearest hospital with cardiology services.

About $90 \%$ of the population of Helena live in the 59601 zip code. The $10 \%$ remaining live in the 59602 zip code, which includes a residential area immediately adjacent to Helena. Many people who live there work in Helena. We surveyed 500 consecutive patients aged over 18 years old who resided in the 59602 zip code and were admitted to the hospital for all causes. Of the 213 of these patients who were employed outside the home, 192 worked in the 59601 zip code area, so we considered 59602 part of Helena for our analyses. We also included zip codes 59604 and 59624 (post office boxes in Helena). All other 596xx zip codes, 59713, and 59728 were considered "not Helena."

\section{Selection of patients}

St Peter's Hospital uses a combination of paper and electronic medical records and computerised billing. We reviewed charts for the months of June to November (the months the ban was in effect) for each year from 1998 to 2003 for patients with a primary or secondary diagnosis of acute myocardial infarction (ICD-9 (international classification of diseases, ninth revision) codes 410.xx). During these months, there were 10497 admissions for all causes (including acute myocardial infarction) from Helena and 3367 from outside Helena. The attending physician made the diagnosis at the time of discharge, and the hospital billing staff assigned the codes. (Two of the authors (RPS and RMS) were attending physicians for 18 of the 304 admissions included in this study and so assigned the diagnosis. All but three of these patients were treated before we thought of doing this study. These three patients were also seen by a cardiologist and thus had independent blinded corroboration of the diagnosis.) Data were sorted by primary and secondary diagnoses and by zip code to compare the incidence of acute myocardial infarction in residents with zip codes for the city of Helena and residents of the surrounding areas, where there was no ban.

We studied patients' charts if there was a primary or secondary discharge or emergency room diagnosis of acute myocardial infarction. Acute myocardial infarction was the primary diagnosis for 283 cases. Selection criteria were onset of symptoms in the study area, a primary diagnosis of acute myocardial infarction, 
and no recent procedure that could have precipitated acute myocardial infarction. We excluded eight cases because onset of symptoms occurred outside the study area and one because the patient died in the emergency room three days after angioplasty. The charts of three patients were reviewed because of multiple admissions in any 60 day period. Of a total of five such admissions, one was excluded because there was no chemical evidence (raised troponin I concentrations or creatine phosphokinase activity) for a new event. We therefore included 274 admissions with a primary diagnosis in the analysis.

We reviewed 71 cases with a secondary diagnosis of acute myocardial infarction. To be included, patients had to have chemical evidence (raised troponin I concentrations or creatine phosphokinase activity) at the time of admission or within the first 24 hours, onset of symptoms inside the study area, and no recent procedure that could have precipitated acute myocardial infarction. In the analysis we included 30 admissions with a secondary diagnosis and excluded 41.

In all cases, we accepted the attending physician's diagnosis of acute myocardial infarction, and all attending physicians (other than the authors) were blinded to the study. In the three cases included after the study was started, a consulting cardiologist who was blinded to the study, confirmed the diagnosis, according to the medical record. We did not change any diagnosis. We excluded or included cases according to the criteria noted above.

We reviewed charts of patients from outside the study area to determine whether onset of symptoms occurred in or out of the study area and included them if the patient's symptoms started in the study area. Twenty six patients in the primary acute myocardial infarction group had out of area zip codes; 14 were included. Eight patients with a secondary diagnosis of acute myocardial infarction had zip codes out of the area. We included three patients with a diagnosis of primary myocardial infarction (for example, primary diagnosis of cardiogenic shock with secondary diagnosis of acute myocardial infarction) whose symptoms had started in the study area.

Overall we selected 354 admissions for review, and 304 met the inclusion criteria.

\section{Statistical methods}

We tested the hypothesis that the law was associated with changes in the total number of admissions for acute myocardial infarction in the six months of June to November (when the law was in effect). We compared the number of admissions during the six months the law was in effect (in 2002) with the average number of admissions during the same six months in the years before (1998-2001) and after (2003) the law.

\section{Results}

During the six months the smoke-free law was in effect (June-November 2002, figure), there was a significant drop in the number of admissions for acute myocardial infarction by -16 admissions (95\% confidence interval -31.7 to -0.3$)$ in Helena. During the same six months in the years before and after the law the average number of admissions was 40 compared with a total of 24 admissions during the six months of the law (table). There was a non-significant increase of 5.6 admissions per month ( -5.2 to 16.4 ) from outside Helena during the same period, from 12.4 before the law compared with 18 during the law. The changes inside and outside Helena were significantly different during these months (table).

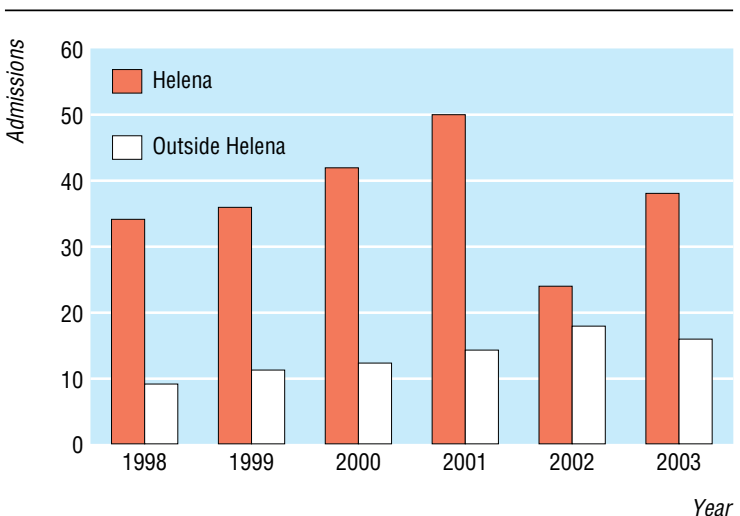

Admissions for acute myocardial infarction during six month periods June-November before, during (2002), and after the smoke-free ordinance (ordinance did not apply outside Helena). The law was implemented on 5 June 2002

\section{Discussion}

During the implementation of a smoke-free law that applied to public places and workplaces we observed a significant drop in admissions for acute myocardial infarction. This is the first study to report such an association. As for any initial report, further research is desirable to confirm the finding. The observations that admission rates fell in the area where the law was implemented but not outside the area, suggests that smoke-free laws not only protect people from the long term dangers of secondhand smoke but also that they may be associated with a rapid decrease in heart attacks.

\section{Strengths of the study}

An important aspect of this study is that it was done in one isolated place with a single hospital that dealt with all admissions for acute myocardial infarction. In most other places that have implemented smoke-free policies, there are several hospitals with people moving across jurisdictional boundaries for work, housing, and health care. These factors "smear out" the effect of any smoke-free policies in both space and time. Data from California, however, could be interpreted as supporting our results. Death rates from heart disease fell faster in California than elsewhere in the United States during the California tobacco control programme, ${ }^{12}$ which, while including a tax increase and media campaign (including the promotion of smoke-free environments), focused on creating smoke-free workplaces and public places. ${ }^{13}$ The fraction of the population covered by smoking restrictions rapidly increased as a result of the campaign, ${ }^{14}{ }^{15}$ and there was a parallel reduction in deaths from heart disease. ${ }^{12}$ Helena's small size and isolation were important contributing factors to our ability to detect a change in admission rates.

Admissions for acute myocardial infarction during six month period (June to November) when smoking ban was enforced and equivalent months in years before and after ban, according to areas with (Helena) and without enforcement*

\begin{tabular}{lrll} 
& \multicolumn{1}{c}{ Helena } & Not Helena \\
\hline Ordinance year $(2002)$ & 24 & 18 \\
\hline Other years $\dagger$ & 40 & 12.4 \\
\hline Difference $(95 \% \mathrm{Cl})$ & -16 & $(-31.7$ to -0.3$)$ & $5.6(-5.2$ to 16.4$)$ \\
\hline
\end{tabular}

Helena difference minus not $\quad-21.6(-40.6$ to -2.6$)$

Helena difference $(95 \% \mathrm{Cl})$

*All comparisons done assuming Poisson distribution.

tAverage number of admissions during six month period for years other than 2002. 


\section{Weaknesses of the study}

Helena's small size can also be an important limitation of the study, as the total number of acute myocardial infarctions we observed was small. The statistical approach to analysis, with the Poisson distribution, does not account for the secular trend of increasing admissions over time (figure) and biases the results towards the null. Despite these small numbers and conservative statistical analysis, however, we were able to detect a significant change associated with the smoke-free law.

This is a "before and after" study that relies on historical controls (before and after the period that the law was in effect), not a randomised controlled trial. Because this study we simply observed a change in the number of admissions for acute myocardial infarction, there is always the chance that the change we observed was due to some unobserved confounding variable or systematic bias.

Our data were from billing records for people who reached the hospital. We reviewed death records for Lewis and Clark County but did not include them because of concern about the accuracy of the assigned causes of death.

The criteria for identifying acute myocardial infarction changed during the study period. In March 1999 St Peter's began using troponin I concentration for diagnosis. To test whether this change could have affected the results, we conducted a regression analysis, including a variable indicating whether troponin I concentration was used; this variable did not approach significance. The change in diagnostic approach does not seem to have affected our results.

We did not make any direct observations to measure how much the exposure to secondhand smoke was reduced during the months when the law was in force. We do not know the prevalence of smoking in venues covered by ban, though the city-county health department reported that all but two businesses complied. ${ }^{16}$

\section{Relation to other studies}

Researchers have predicted that smoke-free laws would be associated with a reduced incidence of acute myocardial infarction through a combination of reduced exposure to secondhand smoke and encouraging smokers to quit ${ }^{11}$ (38\% of the patients with acute myocardial infarction in the study were current smokers, $29 \%$ were former smokers, and 33\% had never smoked at the time of admission). While both of these effects are probably occurring, we do not have a large enough sample size to estimate their relative contribution to our results. Several mechanisms, including increased platelet activation, ${ }^{125}$ inhibition of vascular endothelium, ${ }^{17}$ impairment of coronary artery dilatation capacity, ${ }^{18-21}$ decreases in antioxidant substances (especially ascorbic acid), ${ }^{22}$ aortic stiffening, ${ }^{23}$ and impaired heart rate variability, ${ }^{9}$ all of which could increase the likelihood of an acute coronary event, have been measured within minutes to hours of exposure to secondhand smoke. Even occasional exposure to secondhand smoke has been associated with an increased risk for acute coronary syndromes. ${ }^{24}$

The effect associated with the smoke-free law may seem large but is consistent with the observed effects of secondhand smoke on cardiac disease. Secondhand smoke increases the risk of a myocardial infarction by about $30 \%{ }^{3}$; if all this effect were to occur immediately, we would expect a fall of $-0.30 \times 40.5=-12.2$ in admissions during the six months the law was in effect, which is within the $95 \%$ confidence interval for the estimate of the effect (a drop of -32.2 to -0.8 admissions). Creation of smoke-free environments, as required by the law,

\section{What is already known on this topic}

Secondhand smoke causes acute (within 30 minutes) changes in platelet and vascular endothelial function and reductions in heart rate variability that all increase the risk of an acute myocardial infarction

Epidemiological studies have shown that people living or working in an environment polluted with secondhand smoke have a $30 \%$ increase in risk of acute myocardial infarction

Smoke-free workplace and public place laws rapidly reduce exposure to secondhand smoke

\section{What this paper adds}

In the six months in which a law to ban smoking in the workplace and in public places was enforced in an isolated community, admissions to the local hospital for acute myocardial infarction fell compared with the same months in the years before and after the law was in effect

Smoke-free laws may be associated with a rapid effect on morbidity from heart disease

would also reduce the risk of acute myocardial infarction among those smokers who stop smoking or reduce consumption.

We thank St Peter's Hospital for its cooperation with obtaining the data, particularly Mike Ziegler and Chris Miller for help with data collection and Lisa E Fastnaught and Kurt M Ribisl for assistance in coding the patients' addresses.

Contributors: All three authors made a substantial contribution to the conception, design, analysis and interpretation of data, drafting the article and revising it critically for important intellectual content, and providing final approval of the version to be published. RPS and RMS collected the data, and SAG did the statistical analysis and is guarantor.

Funding: ProtectMontanaKids, a project of the American Cancer Society, American Heart Association, and American Lung Association of the Northern Rockies, with support from the Robert Wood Johnson Foundation. National Cancer Institute Grant CA-61021 and the American Legacy Foundation.

Competing interests: None declared.

Ethical approval: St Peter's Community Hospital Institutional Review Board for Human Research.

1 Glantz SA, Parmley WW. Passive smoking and heart disease: epidemiology, physiology, and biochemistry. Circulation 1991;83:1-12.

Glantz S, Parmley W. Passive smoking and heart disease: mechanisms and risk. JAMA 1995;273:1047-53.

3 He J, Vupputuri S, Allen K, Prerost MR, Hughes J, Whelton PK. Passive smoking and the risk of coronary heart disease-a meta-analysis of epidemiologic studies. $N$ Engl $J$ Med 1999;340:920-6

4 Law M, Morris J, Wald N. Environmental tobacco smoke exposure and ischaemic heart disease: an evaluation of the evidence. BMJ 1997;315:973-80.

5 Glantz S, Parmley W. Even a little secondhand smoke is dangerous. JAMA 2001;286:462-3.

6 Rosenlund M, Berglind N, Gustavsson A, Reuterwall C, Hallqvist J, Nyberg F, et al. Environmental tobacco smoke and myocardial infarction among never-smokers in the Stockholm heart epidemiology program (SHEEP). Epidemiology 2001;12:558-64.

7 Pitsavos C, Panagiotakos DB, Chrysohoou C, Skoumas J, Tzioumis K, Stefanadis C, et al. Association between exposure to environmental tobacco smoke and the development of acute coronary syndromes: the CARDIO2000 case-control study. Tob Control 2002;11:220-5.

Lightwood J, Glantz S. Short term economic and health benefits of smoking cessation: Myocardial infarction and stroke. Circulation 1997;96:1089-96.

9 Pope CI, Eatough D, Gold D, Pang Y, Nielsen K, Nath P, et al. Acute exposure to environmental tobacco smoke and heart rate variability. Environ Health Perspect 2001;109:711-6.

10 Fichtenberg CM, Glantz SA. Effect of smoke-free workplaces on smoking behaviour: systematic review. BMJ 2002;325:188.

11 Ong M, Glantz SA. Cardiovascular health and economic effects of smokefree workplaces. Am J Med (in press).

12 Fichtenberg CM, Glantz SA. Association of the California tobacco control program with declines in cigarette consumption and mortality from heart disease. $N$ Engl J Med 2000;343:1772-7. 
13 California department of Health Services, Tobacco Control Section. A model for change: the California experience in tobacco control. www.dhs.ca.gov/tobacco/documents/ modelforchange.pdf (accessed 4 Aug 2000).

14 Pierce JP, Shanks TG, Pertschuk M, Gilpin E, Shopland D, Johnson M, et al. Do smoking ordinances protect non-smokers from environmental tobacco smoke at work? To $b$ Control 1994;3:15-20.

15 Pierce JP, Evans N, Farkas AJ, Cavin SW, Berry C, Kramer M, et al. Tobacco use in California: an evaluation of the tobacco control program, 1989-1993. San Diego: University of California, 1994.

16 Beckner G. Letter to the editor. Helena Independent Record 2003 Jan 31.

17 Davis J, Shelton L, Watanabe I, Arnold J. Passive smoking affects endothelium and platelets. Arch Intern Med 1989;149:386-9.

18 Sumida H, Watanabe H, Kugiyama K, Ohgushi M, Matsumura T, Yasue H. Does passive smoking impair endothelium-dependent coronary artery dilation in women? J Am Coll Cardiol 1998;31:811-5.

19 Celermajer D, Adams M, Clarkson P, Robinson J, McCredie R, Donald A, et al. Passive smoking and impaired endothelium-dependent arterial dilation in healthy young adults. N Engl J Med 1996;334:150-4.

20 Schachinger V, Britten M, Zeiher A. Prognostic impact of coronary vasodilator dysfunction on adverse long-term outcome of coronary heart disease. Circulation 2000;100:2153-7.

21 Otsuka R, Watanabe H, Hirata K, Tokai K, Muro T, Yoshiyama M, et al. Acute effects of passive smoking on the coronary circulation in healthy young adults. JAMA 2001;286:436-41.
22 Valkonen M, Kuusi T. Passive smoking induces atherogenic changes in low-density lipoprotein. Circulation 1998;97:2012-6.

23 Stefanadis C, Vlachopoulos C, Tsiamis E, Diamantopoulos L, Toutouzas K, Giatrakos $\mathrm{N}$, et al. Unfavorable effects of passive smoking on aortic function in men. Ann Intern Med 1998;128:426-34.

24 Panagiotakos D, Chrysohoou C, Pitsavos C, Papaioannou I, Skoumas J, Stefanadis C, et al. The association between secondhand smoke and the risk of developing acute coronary syndromes, among non-smokers, under the presence of several cardiovascular risk factors: the CARDIO2000 case-control study. BMC Public Health 2002;2:9.

(Accepted 4 February 2004)

doi 10.1136/bmj.38055.715683.55

HealthCare Quality Performance Council, St Peter's Community Hospital, 2475 Broadway, Helena, MT 59601, USA

Richard P Sargent attending physican

Robert M Shepard attending physican

Division of Cardiology, Department of Medicine, University of California, San Francisco, CA 94143-1390, USA

Stanton A Glantz professor of medicine

Correspondence to: S Glantz glantz@medicine.ucsf.edu 